\title{
In the Wake of Japan's Triple Disaster: Rebuilding Capacity through International Collaboration
}

\author{
Eric A. Des Marais \\ Subhasis Bhadra \\ Allen R. Dyer
}

\begin{abstract}
Natural disasters occur when the destructive forces of natural events, such as earthquakes, flood, and volcanoes, overwhelm the capacities of communities. In the winter of 2011, Japan, a model for disaster-preparedness, was shaken by one of the largest earthquakes on record, a ten-story tsunami, and a nuclear emergency on par with Chernobyl. In the acute stages of the disaster, the Japanese government officially asked for help from a number of countries. During this time period, international collaboration played a key role in providing help to survivors in the form of medical assistance, food aid, and psychosocial support. As provision of aid evolved into capacity building, national and local Japanese government agencies, in partnership with local grassroots non-profits, assumed most responsibilities, and international organizations transitioned into new roles. This paper will present a study of the collaboration facilitated by a global non-profit humanitarian organization between international faculty and local partners in Japan.
\end{abstract}

Keywords: Japan, natural disaster, international collaboration, capacity building

\section{INTRODUCTION}

When natural events such as earthquakes, floods, and volcanoes overwhelm the capacity of communities to respond, natural disasters are the result. Natural disasters can result in a massive loss of lives and property for those involved, and it is forecasted that these losses will continue to rise as global population increases and people are forced to move into higher risk regions (Bourney, 2005; Cutter \& Emrich, 2005).

International collaboration around natural disaster mitigation and recovery is typically associated with disasters in developing regions such as Sub-Saharan Africa, the Indian sub-continent, and Southeast Asia. Comparatively, developed countries generally have policies, strategies, programs, and resources in place for disaster mitigation and response. Yet they too can be overwhelmed by natural hazards when the devastation is sufficiently extreme. In these situations, even the best-prepared countries can benefit from international collaboration, especially in the acute and early capacity-building stages of disaster recovery. Such was the case for the Japan's Triple Disaster of 2011.

The goal of this paper is to draw attention to the role that international collaboration can play in the management of massive disaster in developed countries. As a case in point,

Eric A. Des Marais, MSW, LCSW, is a doctoral student in the University of Denver Graduate School of Social Work. Subhasis Bhadra, Ph.D., is an Assistant Professor in the Department of Social Work, School of Humanities and Social Sciences at Gautam Buddha University, India. Allen R. Dyer, MD, Ph.D., is Professor of Psychiatry and Behavioral Sciences at The George Washington University.

Copyright (c) 2012 Advances in Social Work Vol. 13 No. 2 (Summer 2012), 340-357 
it will focus on collaborations facilitated by International Medical Corps between its partners in Japan and international disaster specialists both in the early emergency response phase and the following stage of capacity building efforts. The article will first sketch the events and severity of Japan's Triple Disaster along with the relevant aspects of Japan's disaster management infrastructure. This will be followed with a description of International Medical Corps, a non-profit organization dedicated to strengthening health care capacity after disaster, the international guidelines it follows, and the research base for the psychosocial programs that were introduced in the Japanese context. The next section will describe the collaboration that resulted in the conference, and this will be followed by reflections on the role that social work can play on international and transdisciplinary teams within the context of international disaster response.

\section{METHODOLOGY}

Since the purpose of this article is to describe the collaboration between local partners and international faculty as facilitated by an international organization in the context of Japan's Triple Disaster, a case study approach was adopted. Case studies are particularly good for providing "holistic and context sensitive” analyses (Patton, 2002, p 447). The construction of a case study generally involves three steps: 1) The collection of case data; 2) the organization of the data into a case record; and 3) the development of the case record into a narrative (Patton, 2002).

Data was collected from sources including publicly available reports and documents, presentation materials, and the observations and reflections of the authors, all of whom participated in the organization and presentation of the "Healing a Community: What can we do for our children?” conference held in Sendai, Japan and hosted by Tohoku University School of Education's Department of Clinical Psychology. The collected data was then organized into the following narrative describing the evolution of the collaboration.

\section{JAPAN'S TRIPLE DISASTER}

On March 11, 2011, a Magnitude 9 earthquake, the largest in the history of Japan, occurred $130 \mathrm{~km}$ off the coast of the main island of Honshu (Asian Disaster Reduction Center, 2011). Within ten minutes, a wall of water swelled up, in some places as high as a ten-story building, and slammed into the coast, wiping away bridges, homes, and even entire communities that traced their history back hundreds of years (Earthquake Research Institute, University of Tokyo, 2001; cited in Norris, 2011). News sources estimated that over 400,000 people were left homeless with approximately 25,000 dead, injured, or missing (Central Broadcasting System/Associated Press, 2011). In contrast, the Kobe earthquake of 1995 resulted in approximately 6500 deaths. 
Figure 1. Map of the Disaster Area as of March 29 ${ }^{\text {th }}, 2011$ (From http://file.jishin.yamatoblog.net/map damage.jpg)

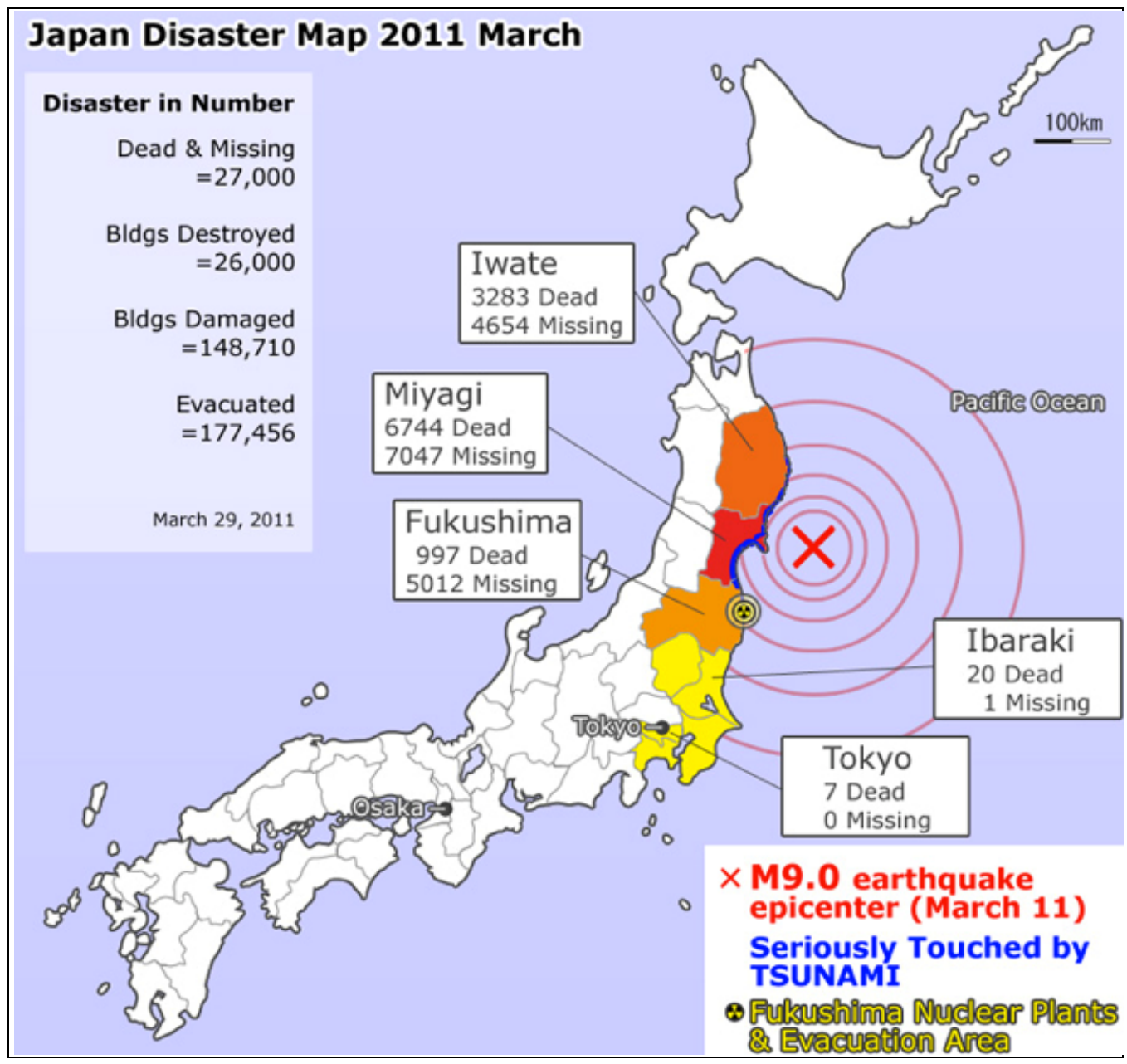

Despite being one of the most prepared nations for massive natural disaster, difficulties were compounded by the meltdown of at least three of the six reactors of the Fukushima Dai-Ichi nuclear power station, creating a nuclear emergency on par with that of Chernobyl. Plumes of radioactive material drifted over large portions of Japan, with radioactive cesium recorded as far north as Japan's northern island of Hokkaido and increased radioactive readings at least as far south as Tokyo. Another 170,000 people were forced to evacuate from a 12-mile radius due to the uncontrolled radiation releases (Harlan \& Mufson, 2011; Physicians for Social Responsibility, n.d.). One government estimate put the total cost of rebuilding at over 300 billion USD, making it the most expensive natural disaster of all time (Zhang, 2011). In the words of Prime Minister Naoto Kan, "In the 65 years after the end of World War II, this is the toughest and most difficult crisis for Japan” (CNN Wire Staff, 2011). 
Japan requested aid from Australia, New Zealand, South Korea, and the United States. By the following week, 128 countries and 33 international nongovernmental organizations (NGOs) had offered support (Nebehay, 2011). International Medical Corps, a global leader in disaster response, was one of the earliest responders to the call for help, beginning the first stages of coordination with the Japanese government, Japanese nonprofit organizations, and local communities within 48 hours (International Medical Corps, 2011b). In the immediacy of the first few weeks, International Medical Corps worked along with local partners PeaceBoat, Second Harvest, Bond \& Justice, Kamaishi Emergency Response Center, and Kesennuma Emergency Response Center to deliver food, medical supplies, and communications equipment to areas affected by the disasters.

A needs assessment concluded that one of the best ways International Medical Corps could collaborate was to provide support and training for Mental Health and Psychosocial Support. Partnering at the request of the Japanese government with the Tokyo English Lifeline (TELL), International Medical Corps thus started the first stage of the Train the Trainers model for Psychological First Aid and facilitated collaborations between international faculty and local partners, culminating in a conference on mental health and psychosocial support for children after the disaster hosted by The Graduate School of Education of Tohoku University in Sendai.

\section{JAPAN'S MODEL FOR DISASTER PREPAREDNESS}

Japan is an epicenter for natural disasters. Located on multiple active faults, having multiple active volcanoes, experiencing typhoons every summer, and being prone to flooding, it is a country that couldn't survive without disaster mitigation and response planning and infrastructure in place. Due to its careful planning, it is considered a model for disaster preparedness (Suganuma, 2006).

At the top of Japan's disaster management infrastructure is the Central Disaster Management Council (CDMC), established by the Disaster Countermeasures Basic Act of 1961 to "ensur[e] comprehensiveness of disaster management and to discuss matters of importance with regard to disaster management" (Government of Japan, 2005; as cited in Pacific Disaster Center, 2006). The CDMC is the major policy engine for disaster management in Japan and is comprised of the Prime Minister, the entire Cabinet, local leaders, and experts in the field (Government of Japan, 2005). It is responsible for designing and implementing national risk management strategies regarding issues of safety, mitigation, and risk reduction (Government of Japan, 2005).

Through the CDMC, the government has engaged in a variety of knowledge building, information dissemination, and capacity building investments (Pacific Disaster Center, 2006). Risk assessments have been performed throughout the country involving public, private, and academic partners. This has resulted in an early warning and monitoring system covering the country. Information products geared for educating a variety of fields and education settings are also in place. This is rounded out by local and national public and private partnerships that mitigate risk through insurance programs, grants, and special loans. 
Thus, for Japan, risk management has been integral to its planning and development processes; yet, there is the issue of what to plan for. Resources are always limited and must be utilized to balance a complexity of needs. The probability of risk and the cost of mitigating it must be balanced against other needs for a society. In the end, the triple disaster of earthquake, tsunami, and nuclear meltdown overwhelmed the preparations that Japan had spent decades putting in place. Many structures, including the Fukushima DaiIchi nuclear complex, were prepared for only a Magnitude 8 earthquake; it was inconceivable that a Magnitude 9 earthquake would occur. Levees and flood barriers were not designed withstand a tsunami that reached 40 meters tall and traveled nearly ten kilometers inland. While Japan had the infrastructure to deal with multiple disasters, it was overwhelmed by the sheer magnitude of the Triple Disaster. Thus, the government of Japan reached out to the embassies of Australia, New Zealand, South Korea, and the United States for assistance.

\section{INTERNATIONAL MEDICAL CORPS: BACKGROUND AND INVOLVEMENT IN JAPAN}

As a result of the request for assistance made to the United States embassy, International Medical Corps, a global humanitarian non-profit organization dedicated to providing health care and training in areas affected by emergency situations, sent a disaster team to Japan within 48 hours to meet with government officials and begin assessing hospitals, government offices and identifying potential partners (Terahata, 2011).

While some health care non-profit organizations build their mission around an approach of relief of immediate needs, International Medical Corps focuses on building local capacity in a "Relief to Self-Reliance" framework (International Medical Corps, 2011a). That is, instead of merely providing aid in emergency situations, International Medical Corps focuses upon building or rebuilding the health care structures of devastated areas. Over the last 25 years, International Medical Corps has responded to many of the greatest humanitarian disasters, including the Soviet invasion of Afghanistan, the famine in Somalia, the genocides in Rwanda, Bosnia and Darfur, the conflicts in the Democratic Republic of Congo and Iraq, the Indian Ocean tsunami, the earthquakes in Pakistan and Haiti and most recently conflict in Libya and the drought in East Africa. Since its founding in 1984, International Medical Corps has delivered more than \$1.1 billion in program services and training to tens of millions of people in more than 65 countries on four continents (International Medical Corps, 2011a).

International Medical Corps participates in a wide range of global collaborations. In 2011, it was a co-chair of the Inter-Agency Standing Committee’s Global Health Cluster and is a part of the Policy and Strategy Team of the World Health Organization. It participated in the Global Humanitarian Platform, which brings together NGOs, the United Nations, and Red Cross and Red Crescent. It is also active in a wide-range of NGO coalitions and networks, including InterAction, the International Council of Voluntary Agencies, and the Humanitarian Caucus of the Global Health Council. 
In light of its goal of building health care capacity with the active involvement of its partners, International Medical Corps first collaborated with the government of Japan on how to interface with local partners. International Medical Corps was paired with Tokyo English Lifeline, a phone line counseling service that provides services to foreigner communities. With its partner, International Medical Corps then worked to build further relationships with other agencies, both in Tokyo and within the affected area, while also performing a needs assessment to identify potential areas for collaboration that matched both International Medical Corps' expertise and the needs of the local communities.

In the first few days, it became clear that there were a variety of hurdles to be overcome, including difficulty in reaching the affected area due to fuel shortages and damage to transportation infrastructure, difficulties in obtaining accurate information, and lack of communication equipment between evacuation centers and Prefectural offices (Terahata, 2011). Thus, in the first days, it was difficult to reach the affected area. As the days wore on, International Medical Corps prioritized work with local agencies and nonprofits engaging in relief efforts (Terahata, 2011). The International Medical Corps team met with Miyagi Prefecture officials, administrators at local hospitals, evacuation centers, city council members, search and rescue teams, the prefectural health response coordinator, and attended Japan Platform and JANIC meetings (Terahata, 2011).

This first phase of intervention focused on relief efforts. International Medical Corps worked to improve data and communication infrastructure by providing prefectural offices, regional coordination centers, and evacuation centers with computers and data cards (Terahata, 2011). Working with local partners, the disaster team also provided and dispersed medical supplies and hot meals to over 20,000 people living in five evacuation centers (Terahata, 2011). Japanese NGOs were also supplied with rental cars and computers to build their capacity to provide health services in the affected area (Terahata, 2011).

As the needs assessment reached completion, International Medical Corps then began to move its focus to capacity building. Adhering to the Inter-Agency Standing Committee's Guidelines for Mental Health and Psychosocial Support (IASC, 2007), International Medical Corps engaged with its partners to build capacity for mental health support. These included, at the request of the Japanese government, partnering with the Tokyo English Lifeline (TELL) to start the cascade of Training the Trainers for Psychological First Aid (PFA), and a sensitization to psychosocial support needs workshop hosted by Tohoku University’s Graduate School of Education in Sendai, Japan.

\section{PSYCHOLOGICAL FIRST AID AND PSYCHOSOCIAL SUPPORT}

Psychological First Aid (PFA) is the most accepted approach widely used to facilitate psychological healing of the survivors of any disaster or critical event. In international guidelines, the provision of PFA is recommended for survivors as well as for the disaster intervention workers. "Psychological First Aid is an evidence-informed modular approach for assisting children, adolescents, adults, and families in the immediate aftermath of disaster and terrorism. Psychological First Aid is designed to reduce the 
initial distress caused by traumatic events, and to foster short- and long-term adaptive functioning” (National Child Traumatic Stress Network and National Center for PTSD, September, 2005). There is a range of standards for which persons should practice psychological first aid, but the essential principle is that the person should be trained in Psychological First Aid and be supervised by a mental health professional. Psychological First Aid is a culturally competent approach and is applicable across populations of different age groups. The Inter-Agency Standing Committee's (IASC) Mental Health and Psychosocial Support (MHPSS) guidelines recommend making available psychological support for survivors of extreme stressors (Inter Agency Standing Committee (IASC), 2007). The guidelines also outline the basic features of PFA. Psychological First Aid identifies key techniques for helping survivors of mass trauma including: 1) protecting them from further harm; 2) providing opportunities for survivors to talk; 3) listening carefully, patiently, and conveying genuine compassion; 4) identifying and providing basic needs; 5) encouraging positive coping and participation in daily routine activities; and 6) facilitating local support mechanisms. The personnel trained in providing PFA are also encouraged to consider mental health referral in the case of higher distress or for the vulnerable sections of the surviving community.

Psychosocial support for disaster survivors is a range of work that has gained a lot of momentum as a disaster intervention in the past two decades and subsequently more importance is given to facilitate psychosocial recovery of the survivors. Psychosocial support is "any type of local or outside support that aims to protect or promote psychosocial well-being and/or prevent or treat mental disorder" (IASC, 2007). In the 2011 Sphere Handbook, psychosocial support is considered as one of the important cross cutting themes, a step forward from the previous version in which psychosocial support was considered under health sector interventions. "Some of the greatest sources of vulnerability and suffering in disasters arise from the complex emotional, social, physical and spiritual effects of disasters" (Sphere Project, 2011) that need to be supported with a structured psychosocial support program.

The Guidelines for Mental Health and Psychosocial Support in Emergency Settings (IASC, 2007) considered four aspects as core to psychosocial support interventions, namely 1) community mobilization and support, 2) health services, 3) education, and 4) dissemination of information. Community mobilization focuses on developing community participatory processes of recovery, developing self-help among the survivors, resiliency-building activities, and culturally appropriate methods of healing practices. In contrast, approaches within the health sector emphasize integrating mental health support into the general health care system by multiple layers of training of health professionals, facilitating specialized care for the mentally ill, collaborating with local mental health resources, and reducing the harmful use of alcohol and substance use.

Regarding educational intervention, safe and supportive education should be promoted. Providing the right information at the right time is an important precondition as lack of actual information causes stress and worry for survivors. Further, giving practical and appropriate information can ensure actual use of resources as well as providing knowledge to the survivors about their future. The community based psychosocial support training manual describing psychosocial support refers to the 
dynamic relationship between the psychological and social dimension of a person, where the one influences the other (International Federation Reference Centre, 2009). The psychological dimension includes the internal, emotional and thought processes, feelings and reactions. The social dimension includes relationships, family and community networks, social values and cultural practices. Psychosocial support refers to the actions that address both the psychological and social needs of individuals (Hansen, 2008). The provision of psychosocial support ensures reduction of distress, associated disability and facilitate psychosocial wellbeing. Psychosocial wellbeing is considered as a combination of three domains of human life: 1) human capital (which deals with physical and mental health and an individual's capacity to realize his own strength); 2) social ecology (social connections, networks, and relationships that promote cohesion and equilibrium in society); and 3) culture and values (societal norms and behavior connected with social expectations) (Psychosocial Working Group, 2003). Psychosocial wellbeing is largely connected with environmental, economic and physical resources that support existence and wellbeing (Psychosocial Working Group, 2003).

\section{PSYCHOSOCIAL SUPPORT STRATEGIES IN INDIA AND JAPAN}

Psychosocial support, while being accepted as the most crucial aspect of psychological recovery for the disaster survivors across the world, equally stresses cultural adaptability in the approach. The Indian Ocean Tsunami of 2004 was a unique disaster impacting about seven countries that lead to a major change and wider acceptance of psychosocial support activity at this region. For a long period of time, psychosocial support was meshed with the identification and treatment of patients with severe mental disorders, which was replaced with the community-oriented approach that focused on wellness rather than illness and proved that, for every survivor of disaster who are exhibiting higher stress reactions, mental health support is needed. This was a major paradigm shift from the medical model to the psychosocial model (Satapathy \& Bhadra, 2009). India was one among the worst hit countries in South Asian Tsunami of 2004 and focused a great deal on the facilitation of large-scale mental health care in communities and schools by mobilizing large numbers of volunteers and workers from different government departments as well as by continuous capacity building and follow-up (World Health Organization, 2006). India, being a developing nation, was clearly in need of multiple supports for rebuilding and, as is generally the case, a huge international response arrived that mainly prioritized the physical needs. Mental health and psychosocial support was still not a focus outside of a few international organizations. The National Institute of Mental Health and Neurosciences in Bangalore (NIMHANS), being the premier institute and nodal center for psychosocial support, took a major initiative of facilitating technical support for psychosocial work with national, international and government organizations (Sekar, 2006). As a basic strategy of work for psychosocial support, local NGOs and government departments were engaged through the involvement of a large number of community level workers (e.g. teachers, child care personnel, health workers, community leaders, representatives of local self-government, student volunteers, volunteers from different forum, self help group members, members of religious institutions). It was this active interest and engagement of the survivors in the program that lead to an agenda for long-term support. During this phase it was also 
realized by the Indian Government that lack of accepted Indian Guidelines hampered the flow of services and desired outcome that called for immediate government action for national level guidelines on mental health services and psychosocial support for disaster response (Government of India, December, 2009). Indian coastal communities and administrative systems were grossly unaware of the tsunami and an absolute lack of a warning system caused a major damage and vulnerability even after the disaster. The long-term psychosocial support program supported by various funding sources showed a major change in the condition and created awareness about wellbeing, practicing safety measures, and developing community strength to deal with adversity.

Japan, one of the countries most prepared for disaster, has a long history of withstanding multiple disasters and has developed a strong system of governance to deal with the effects of disaster. Japan is well equipped with a tsunami-warning infrastructure along with earthquake and flood safety measures, and its core knowledge and skill have progressed far ahead of many Asian countries in its technology and its implementation. The government of Japan, as well as local professionals, has dealt with a number of disasters events very effectively. It is considered a model for dealing with adversity by developing resiliency within its communities. Therefore, community engagement in disaster safety measures and disaster preparedness is a practiced approach in Japan.

However, the triple disaster that stuck northern Japan was much more than what its communities were prepared for. In these overwhelming events, psychosocial support for the community becomes a critical need as the disasters shook the confidence of the communities. Usually, the physical aspect of disaster preparedness ensures a major psychological strength that encourages the survivors to deal with the adversities. The Triple Disaster exposed survivors to conditions they were unable to cope with, namely the traumatic experience and the need for external support (Levin, 2011). The experience of International Medical Corps in responding to tsunami survivors worldwide has shown that the community-based mental health care and support for the disaster survivors is not a widely practiced approach; hence the clinical infrastructure wouldn't be sufficient to deal with the emotional needs of the survivors. Further, for all people, emotional needs can be immense in cases of traumatic experiences, grief, or loss, irrespective of the advancement of the society in socioeconomic or technological spheres. Therefore, the applicability and essence of community-based psychosocial support to reach out to all the survivors to facilitate mental health care should have some similarity to the 2004 Indian tsunami experience.

A comparison between India and Japan regarding post-tsunami psychosocial support would suggest that the Indian model of psychosocial support that worked at individual, family, and community level through various interventions would also be effective in Japan, as many cultural factors are similar, such as strong community and family relationships, living with extended family networks, family decision-making processes and cohesive living. At the individual level, the sense of responsibility to family members is very high and gender roles are more defined; thus, it is likely there are similar pattern of stress among the survivors in both countries. Hence, a model of psychosocial support that encourages rebuilding the eroded support system, reducing stress reactions, 
encouraging positive coping, restoring normalcy, and developing sustainable communitybased mental health care is crucial.

However, there are also cultural differences that must be considered. First, India is an amalgam of ethnicities and religious orientations with two official languages and multiple regional languages. Japan, on the other hand, is homogeneous with $98.5 \%$ of the population being ethnic Japanese. There is of course regional distinction and pride in Japan, but this has resulted in little overt competition between groups. While this amount of social cohesion leads to accusations of over-conformity by critics, it appears to have been a factor in community resilience in the case of the Triple Disaster. Unlike many disasters, there has been no rioting, and only minor instances of looting. While there is no clear evidence of how these cultural differences would affect the implementation of a Psychological First Aid or Psychosocial Support program, it is important that IASC guidelines for cultural respect and inclusion of local organizations and groups be kept in the forefront.

Another key distinction between the cases of India and Japan is the level of health care infrastructure between the two countries. Japan in relation to India has a much more developed health care system. In the 2000 ranking by the World Health Organization (2000), Japan ranked in the top ten while India was ranked much lower on the scale. Thus, while the dissemination innovations spearheaded by NIMHANS were fitting for the Indian context, it is likely that adjustments would need to be made based on the differing context of Japan's public health system.

\section{IMPLEMENTATION OF PSYCHOLOGICAL FIRST AID AND PSYCHOSOCIAL SUPPORT}

International Medical Corps' needs assessment identified need in the area of building capacity for managing psychological stresses resulting from the Triple Disaster. As one of the key factors in successful implementation of mental health and psychosocial support programs is that the programs be shaped by the needs of the community, it was incumbent upon International Medical Corps to work with its local partners during this phase. Key facets of this stage involved starting the "cascade" of the Training of the Trainers model for Psychological First Aid and organizing a sensitization workshop for psychosocial support for teachers, community and school mental health practitioners, and graduate students offering volunteer support to survivors and relief workers.

\section{Cascading Training of Trainers}

Psychological First Aid is an evidence-based practice that is designed for immediate implementation after a disaster. It is designed in such a way that training is efficient and practical, allowing it to be spread quickly and widely. It uses a Training of Trainers (TOT) model, ideally creating a cascade that results in implementation on a meaningful scale. Once the training is completed, participants have an understanding of how to deliver PFA, how to engage with survivors, how to address safety and comfort, stabilization, gathering information from survivors, providing practical assistance, 
utilizing social supports, coping, and self-care to prevent secondary trauma for the care providers (Brymer, et al, 2006).

An International Medical Corps advisor in Mental Health and Psychosocial Support (MHPSS) was sent to Japan to train the Tokyo English Lifeline (TELL) counselors in PFA and to guide the first phase of the intervention. Once the counselors at TELL had completed the training, they were then able to offer appropriate support to their client base and TELL was able to begin training others in the affected communities. While the preliminary training occurred in Tokyo, the next trainings were more directly focused on care providers in the disaster area. As TELL gained confidence with the material and the training, responsibility shifted to their organization to carry on the Training of Trainers model.

TELL integrated IASC guidelines into their training curriculum through the PFA trainings. When TELL took over the training, they quickly began training a wide range of volunteers, phone counselors, company employees, teachers, and parents. International Medical Corps supported these capacity efforts by funding nine workshops for 150 employees on coping strategies and eight workshops for parents and teachers focused on creating supportive environments for children after disaster (Terahata, 2011).

\section{Sensitization to Psychosocial Support Conference}

While Psychological First Aid is appropriate for immediate responses to psychological and emotional needs after a disaster, longer-term psychosocial needs become evident after the initial stages of disaster. Thus, at the request of the Graduate School of Education of Tohoku University, International Medical Corps and Tokyo English Lifeline worked in collaboration to hold a two-day conference geared for sensitizing school teachers, community-level mental health workers, social workers, clinical psychology graduate students, academics, and other community members on what might be expected in terms of helping children in the middle term of the next few months and over the long term of the next few years. The team that organized and presented the conference consisted of mental health practitioners and faculty from India, the United States, and Japan who all have expertise and experience in interventions for managing the psychosocial needs of adults and children who have faced traumatic experiences. While much of the material covered was perhaps not new to this specific audience, in the words of one of the conference organizers, the workshop, "gave us hope." That is, it helped reassure them in their own abilities and knowledge base in dealing with overwhelming amount of work to be done, and showed them that they are not alone in dealing with the trials and tribulations of natural disasters.

The first day of the workshop provided a basic overview of range of considerations that arise after a disaster, focusing specifically on the psychosocial needs of survivors. Sessions focused on outlining lessons learned from previous disasters including what to expect in terms of the epidemiology of trauma, the stages of grief, life skills for disaster, an introduction to Psychological First Aid and psychosocial support, and delineation between clinical-level mental health care versus psychosocial support techniques (Bhadra \& Kasi, 2011; Bharath, 2011; Dyer, 2011). 
The second day of the workshop reinforced and expanded many of the ideas presented on the first day. The Humanitarian Charter and Minimum Standards in Disaster Response (which defines standards for humanitarian response and rights of survivors) and IASC guidelines for mental health and psychosocial support were presented, highlighting that the guidelines were not treatment manuals, but a baseline from which to start (IASC, 2007; Sphere Project, 2011). Further sessions focused on children's stages and expression of grief, creating classroom environments that helping children heal from trauma as opposed to punishing them for acting out, and differentiating between clinically significant posttraumatic stress syndrome (PTSD) and stress as a "normal reaction to abnormal circumstances” (Bhadra, 2011; Bharath, 2011; Des Marais, 2011; Dyer, 2011, Kasi, 2011). The final afternoon had four tracks. One track provided an experiential presentation for working with children by using art and play to help them express and process their emotion (Bhadra, 2011). Another track focused on life skills for managing stress from disaster (Bharath, 2011). A third track provided a more in-depth exposure to PFA (Takahashi, 2011a, 2011b).

The final track, which focused on policy and planning, was based upon the experiences of the NIMHANS in managing psychosocial care in the early (days to weeks), middle (months), and long terms (years) of the response (Dyer, 2011; Kasi, 2011; Kasi, Bhadra, \& Dyer, 2007; Kasi, Dyer, \& Bhadra, 2011). It identified four stages of psychosocial care, moving from psychological first aid for the acute stages of the disaster, to psychosocial support and psychosocial care for managing longer terms symptoms of trauma, and finally the stage of psychosocial rehabilitation for those experiences the more extreme cases of PTSD. This track provided policy makers with a way to look forward and begin to prepare for the next stages of intervention.

Unlike the Psychological First Aid Training, the conference was not designed as a Train the Trainers model. Its purpose was to provide a frame and context for anticipating what issues are likely to arise in the middle and long terms and to examine possible options for addressing those mental health and psychosocial needs. Especially important in terms of looking forward was the future policy considerations that were presented in track four. While the presenters' previous experience in disaster management in India and China were designed to be helpful for the participants, there are a wide range of unknowns in any major catastrophe as well as gaps in knowledge regarding individual and community resilience in the face of disaster, managing stress and trauma, and cultural differences in dealing with psychosocial stress. 
Figure 2. Sensitization to Psychosocial Support Sessions (This figure illustrates the sessions and tracks of the workshop.)

\begin{tabular}{|c|c|c|c|c|c|c|}
\hline & \multicolumn{2}{|l|}{ Day 1} & \multicolumn{4}{|l|}{ Day 2} \\
\hline & Time & Plenary sessions & \multicolumn{4}{|c|}{ Plenary sessions } \\
\hline \multirow[t]{5}{*}{ Morning } & $11.00-11.10$ & Welcome address & $11.00-11.30$ & \multicolumn{3}{|c|}{ To Remember or to Forget } \\
\hline & $11.10-1.45$ & $\begin{array}{l}\text { Introduction to IMC and } \\
\text { Japan work } \\
\text { NIMHANS at a Glance } \\
\text { Introduction of TELL }\end{array}$ & $11.30-12.15$ & \multicolumn{3}{|c|}{$\begin{array}{l}\text { Sphere and IASC guidelines on } \\
\text { MHPSS in emergency settings }\end{array}$} \\
\hline & $11.45-2.15$ & $\begin{array}{l}\text { A Decade of Disasters: } \\
\text { Lesson from Indian and } \\
\text { US Experiences }\end{array}$ & $12.15-12.40$ & \multicolumn{3}{|c|}{$\begin{array}{l}\text { Children, Adolescents, and } \\
\text { Traumatic Events: Managing } \\
\text { Behaviors in the Classroom }\end{array}$} \\
\hline & 12.15- 1.00 & $\begin{array}{l}\text { Normalization of } \\
\text { Reactions }\end{array}$ & $12.40-01.00$ & \multicolumn{3}{|c|}{ PTSD or Not? } \\
\hline & Time & Plenary sessions & \multicolumn{4}{|c|}{ Workshops (02.00-05.00) } \\
\hline \multirow{7}{*}{ Afternoon } & $02.00-2.45$ & Stages of Grief and Loss & Track 1 & Track 2 & Track 3 & Track 4 \\
\hline & $02.45-3.30$ & $\begin{array}{l}\text { Psychosocial support in } \\
\text { Disaster Management } \\
\text { (Principles) }\end{array}$ & $\begin{array}{l}\text { PFA for } \\
\text { Disaster } \\
\text { Care }\end{array}$ & $\begin{array}{l}\text { Life Skills } \\
\text { Education }\end{array}$ & $\begin{array}{l}\text { Working } \\
\text { with } \\
\text { Children }\end{array}$ & $\begin{array}{l}\text { Policies } \\
\text { and } \\
\text { programs }\end{array}$ \\
\hline & & $\begin{array}{l}\text { Psychosocial support in } \\
\text { Disaster Management }\end{array}$ & & & & \\
\hline & 04.30-5.15 & Introduction to PFA & & & & \\
\hline & 05.15- 6.00 & $\begin{array}{l}\text { Introduction to Life } \\
\text { Skills Education }\end{array}$ & & \multicolumn{3}{|c|}{ Presentation by each group } \\
\hline & & & 05.40-05.50 & \multicolumn{3}{|l|}{ Evaluation } \\
\hline & & & 05.50-06.00 & \multicolumn{3}{|c|}{ Concluding remarks and thanks } \\
\hline
\end{tabular}

\section{SOCIAL WORK, DISASTER INTERVENTION, AND INTERNATIONAL COLLABORATION}

The definition of the social work profession given in the final document adopted at the general assemblies of IASSW and IFSW in Adelaide, Australia in 2004 states the imperative of social workers to aid the survivors of disaster:

The social work profession promotes social change, problem solving in human relationships and the empowerment and liberation of people to enhance wellbeing. Utilizing theories of human behavior and social systems, social work intervenes at the points where people interact with their environments. Principles 
of human rights and social justice are fundamental to social work. (Sewpaul and Jones, 2005, p. 218).

In a disaster where death, destruction, and damage are common, human life is affected severely in many dimensions. The material needs of food, clothing, housing, livelihood and medical care are common, but there are a number of non-material needs, which must also be recognized to ensure the well-being of the survivors. Disaster imposes problems not only for the survivors but also for government organizations, professionals, and others. Therefore, disaster intervention work is a major problem solving effort to re-establish social support and human relationships to empower people to achieve a sense of well-being, necessitating trans-disciplinary collaboration. The core skills of social work are needed on these inter-professional teams, along with those of psychiatrists, physicians, nurses, psychologists, and other disaster workers to support the psychosocial well-being of the disaster survivors in different phases of the disaster, i.e. rescue, relief, rehabilitation and rebuilding (Bhadra, 2010). Social workers are particularly well-prepared for the rehabilitation phase, which is usually from three months until 1 to 2 years post-disaster. During this phase, there is a strong need for contextualized culturally appropriate materials, capacity building for psychosocial support/ psychological first aid (requiring clinically trained social workers and other master trainers), specialized program for the vulnerable (women, children, disabled, families with diseased member, etc), support for translation of the knowledge of capacity building to actual skills, stress management for the disaster intervention workers, and action research and case studies to develop more focused programs. In the case of the "Healing a Community" conference, the objective was towards enhancing the confidence of the participants to respond to the rehabilitation needs more effectively and efficiently.

\section{JAPAN AFTER THE TRIPLE DISASTER}

As the case of Japan's Triple Disaster shows, even the most highly developed and well-prepared nations can be overwhelmed by cataclysmic events. In this case, an earthquake began a cascade of events that culminated in one of the worst nuclear disasters in history and the displacement of over 500,000 people. One year after the Triple Disaster, Japan is on the road to recovery - everyone has been moved out of shelters, towns are being rebuilt, resettlement projects are being formulated, and even more advanced disaster preparations are being put in place. However, it is a long road, and without key international collaboration in the early stages, it is hard to imagine that Japan would be even this far along.

Whether termed "wicked problems", “cascades of failure", or "complex emergencies", when the resilience of social and ecological systems is overwhelmed by multiple stressors, interventions must be applied on multiple levels. While this paper highlights the development of one such set of collaborations that was geared specifically for reinforcing and increasing psychosocial support in the devastated Tohoku region, it must be stressed that it occurred within a context of many other interventions also being put in place. Volunteers, health and mental health practitioners, logistic specialists, government officials, and others from multiple nations, domestic and international non- 
profit organizations, businesses, and civil society groups have all worked together for a common goal of the restoration of the Tohoku region.

Looking at the broader context of increased globalization, continued population growth, depletion of non-renewable resources, losses in biodiversity, and predicted increases in natural disaster due to climate change, international and inter-professional collaboration are key to managing systems so that all people can flourish. No one country or profession possesses the resources, expertise, or wisdom to address these systemic issues on their own; the path to solutions lies in cooperative exchanges like those presented here. At the same time, it is important that these exchanges serve to reinforce local residents and support their decision-making capabilities. As is the case in Japan's Triple Disaster, those affected by the events should be the final arbiters of the evolution of these collaborations.

\section{References}

Asian Disaster Reduction Center, International Recovery Platform. (2011). Great East Japan Earthquake: Update on damage and recovery $\left(2^{\text {nd }}\right.$ Report $)$.

Bhadra, S. (2010). Social work and disaster interventions. In B. S. Gunjal \& G. M. Molankal (Eds.), Fields of social work practice (pp. 355-386). Bangalore: Baraha Publishing House.

Bhadra, S., \& Sekar, S. (2011). Grief among the children and recovery [Powerpoint presentation]. Retrieved from https://sites.google.com/site/imcsendai/

Bhadra, S. (2011). SPHERE and IASC guidelines on mental health and psychosocial support in emergency setting [Powerpoint]. Retrieved from https://sites.google.com/site/imcsendai/

Bharath, S. (2011). Disaster and life skills education in children [Powerpoint presentation]. Retrieved from https://sites.google.com/site/imcsendai/

Bourney, E. (2005). Trends in natural disasters. UNEP/GRID-Arendal Maps and Graphics. Retrieved from http://maps.grida.no/go/graphic/trends-in-naturaldisasters.itle

Brymer, M., Jacobs, A., Layne, C., Pynoos, R., Ruzek, J., Steinberg, A., Vernberg, E., \& Watson, P. (2006). Psychological first aid: Field operations guide ( $2^{\text {nd }}$ ed.). Los Angeles, CA: National Child Traumatic Stress Network.

Cable News Network Wire Staff. (2011, March 14). Anxiety in Japan grows as death toll steadily climbs. Cable News Network. Retrieved from http://www.webcitation.org/5xtOp7djK.

Central Broadcasting System/Associated Press. (2011, March 16). Japan death toll climbs: Half a million homeless. CBS World News. Retrieved from http://www.cbsnews.com/stories/2011/03/16/501364/main20043730.shtml.

Cutter, S. L., \& Emrich, C. (2005). Are natural hazards and disaster losses in the U.S. increasing? Eos, 86(41), 381-396. doi:10.1029/2005EO410001 
Des Marais, E. (2011). Children, adolescents, and traumatic events: Managing behaviors in the classroom [Powerpoint presentation]. Retrieved from https://sites.google.com/site/imcsendai/

Dyer, A. (2011). Stages of grief [Powerpoint presentation]. Retrieved from https://sites.google.com/site/imcsendai/

Earthquake Research Institute, University of Tokyo. (2011). 2011 Tohoku Earthquake. Retrieved from http://outreach.eri.u-tokyo.ac.jp/eqvolc/201103_tohoku/eng

Government of India. (2009, December). National disaster managment guidelines, psychosocial support and mental health services in disasters. New Delhi: A Publication of National Disaster Managment Authority, Government of India.

Government of Japan. (2005). National report of Japan on disaster reduction. United Nations International Strategy for Disaster Reduction. World Conference on Disaster Reduction. Retrieved from http://www.unisdr.org/2005/mdgs-drr/nationalreports/Japan-report.pdf

Hansen, P. (2008). Psychosocial interventions: A handbook. (W. Agen, Ed.). Copenhagen: International Federation Reference Centre, for Psychosocial Support.

Harlan, C., \& Mufson, S. (2011, March 13). Japanese nuclear plants' operator scrambles to avert meltdowns, The Washington Post. Retrieved from http://www.washingtonpost.com/wpdyn/content/article/2011/03/12/AR2011031205493.html

Inter Agency Standing Committee (IASC). (2007). Mental health and psychosocial support in emergencies (MHPSS). Geneva: Author.

International Federation Reference Centre. (2009). Community-based psychosocial support: Participant's book. Copenhagen: International Federation of Red Cross and Red Crescent Societies Reference Centre for Psychosocial Support.

International Medical Corps. (2011a). International Medical Corps' mission: From relief to self-reliance. Retrieved from http://internationalmedicalcorps.org/section/about

International Medical Corps. (2011b). International Medical Corps still on the ground, helping Japan rebuild. Retrieved from http://internationalmedicalcorps.org/japan

Kasi, S. (2006). Psychosocial care for survivors of disasters: past, present, and Future. 1st India Disaster Management Congress (pp. 1-3). New Delhi: National Institute of Disaster Managment.

Kasi, S., Dyer, A., \& Bhadra, S. (2011). Psychosocial support in disaster management [Powerpoint presentation]. Retrieved from https://sites.google.com/site/imcsendai/

Kasi, S., Bhadra, S., \& Dyer, A. (2007). A decade of disasters: Lessons from the Indian experience. Southern Medical Journal, 100(9), 929-931.

Levin, A. (2011, June 3). Japan's resilience eases impact of natural disaster. Psychiatric News , 46(11), pp. 1-4. 
National Child Traumatic Stress Network and National Center for PTSD. (2005, September). Psychological first aid: Field operations guide. Los Angeles, CA: Author.

Nebehay, S. (2011, March 11). Japan requests foreign rescue teams, UN says. Reuters. Retrieved from http://www.reuters.com/article/2011/03/11/us-japan-quake-aid-refileidUSTRE72A71320110311

Norris, D. (2011, April 7). Japan's tsunami topped 37 meters. Science Insider. Retrieved from http://news.sciencemag.org/scienceinsider/2011/04/japans-tsunami-topped-37meters.html

Pacific Disaster Center. (2006). Kobe, Japan. Disaster Risk Management Profile. Retrieved from http://www.pdc.org

Patton, M. Q. (2002). Qualitative research \& evaluation methods. $3^{\text {rd }}$ Edition. Thousand Oaks, California: Sage Publications.

Physicians for Social Responsibility. (n.d.). Lessons from Fukushima: Still dangerously unprepared. Washington, DC: Author.

Psychosocial Working Group. (2003, October). Psychosocial intervention in complex emergencies: A conceptual framework. Edinburgh: Author.

Satapathy, S., \& Bhadra, S. (2009). Disaster psychosocial and mental health support in South \& South-East Asian countries: A synthesis. Journal of South Asian Disaster Studies, 2(1), 21-45.

Sewpaul V., \& Jones, D. (2005). Global standards for the education and training of the social work profession. International Journal of Social Welfare, 14(3), 218-230.

Sphere Project. (2011). The Sphere Handbook: Humanitarian charter and minimum standards in humanitarian response. United Kingdom: Author. Retrieved from http://www.spherehandbook.org/

Suganuma, K. (2006). Recent trends in earthquake disaster management. Quarterly Review of the Science and Technology Foresight Center, No. 19, 91-106.

Summerfield, D. (2000). War and mental health: A brief overview. British Medical Journal 3121(7255), 232-235

Takahashi, C. (2011a). Psychological first aid 1 [Powerpoint presentation].

Takahashi, C. (2011b). Psychological first aid 2 [Powerpoint presentation].

Terahata, Y. (2011). Humanitarian assistance/disaster relief. Presentation to Japan-USSouth Korea Civil-Military Disaster Preparedness Workshop. International Medical Corps, September 29, 2011.

World Health Organization. (2000). The World Health Report 2000: Health systems: Improving performance. pp. 1-215. Geneva, Switzerland: Author. 
World Health Organization. (2006). Psychosocial support for tsunami affected populations in India. Non Communicable Diseases and Mental Health Cluster. New Delhi: WHO Country Office, India.

Zhang, B. (2011, March 30). Top 5 most expensive disasters in history. Accuweather.com. Retrieved from http://www.accuweather.com/blogs/news/story/47459/top-5-mostexpensive-natural-d.asp.

\section{Author note:}

Address correspondence to: Eric A. Des Marais, University of Denver Graduate School of Social Work, 2148 South High Street, Denver, CO 80208. Email:

Eric.DesMarais@du.edu 